\title{
Passenger Car Equivalents for Heavy Vehicles at Roundabouts. a Synthesis Review
}

\author{
Orazio Giuffrè ${ }^{1}$, Anna Granà ${ }^{1 *}$, Tullio Giuffrè ${ }^{2}$, Maria Luisa Tumminello ${ }^{1}$ and \\ Francesco Acuto $^{1}$
}

${ }^{1}$ Department of Engineering, University of Palermo, Palermo, Italy, ${ }^{2}$ Faculty of Engineering and Architecture, Kore University of Enna, Enna, Italy

Passenger Car Equivalents (PCEs in the following) are used to transform a mixed fleet of vehicles into a fleet of equivalent passenger cars and to analyze capacity and levelof-service of roads and intersections. Most roundabouts guidelines propose constant values for PCEs but a single PCE value can result improper under heterogeneous traffic conditions. PCEs should be vary with traffic and road conditions and consequently PCEs applied to undersaturated traffic conditions can overestimate the heavy vehicle effect or be not sensitive to the traffic level or characteristics of heavy vehicles. Compared to other at-grade intersections, the interaction between the operational performances of the heavy vehicles and the geometric features at roundabouts can produce significant

OPEN ACCESS

Edited by:

Sakdirat Kaewunruen, University of Birmingham, United Kingdom

Reviewed by:

Ferdinand Fassa,

Podomoro University, Indonesia

Marco Guerrieri

University of Trento, Italy

${ }^{*}$ Correspondence:

Anna Granà

anna.grana@unipa.it

Specialty section:

This article was submitted to Transportation and Transit Systems,

a section of the journal

Frontiers in Built Environment

Received: 25 April 2019

Accepted: 31 May 2019

Published: 18 June 2019

Citation:

Giuffrè $O$, Granà A, Giuffrè T,

Tumminello ML and Acuto F (2019)

Passenger Car Equivalents for Heavy Vehicles at Roundabouts. a Synthesis

Review. Front. Built Environ. 5:80.

doi: 10.3389/fbuil.2019.00080 impacts on the heavy vehicle paths and traffic operations due to the curvilinear nature of the roundabout design. Literature presents various methods of estimation to obtain PCE values for heavy vehicles. The focus of this paper is to review statistical methods and traffic simulation studies based on microscopic approaches used to calculate PCEs for heavy vehicles driving roundabouts. Effects on capacity and estimates of PCEs based on models currently employed in roundabout analysis are also compared. The results obtained in this study aim at providing an overview of the existing knowledge concerning the estimation of PCEs at roundabouts and can represent a guideline for transportation engineers in planning, design and capacity analysis of roundabouts that operate under conditions of mixed traffic.

Keywords: passenger car equivalent, roundabout, capacity, heavy vehicles, statistical methods, microsimulation

\section{INTRODUCTION}

Empirical evidence shows that the structure of traffic patterns makes operational conditions on highways, roads and intersections far from ideal conditions such as the Highway Capacity Manual $(2000 ; 2010 ; 2016)$ describes. Heterogeneity of drivers, users and vehicles interacting with each other in traffic has effect both on the levels of operational quality and on safety conditions of road entities (e.g., Kiran and Verma, 2016; Asaithambi et al., 2017). Interaction among vehicles having various sizes, and static and dynamic features could also affect the accuracy of whatever traffic assessment and management application (Raj et al., 2019). Studies and researches, as literature in the field of transportation engineering refers, report that the impact of heavy vehicles in mixed traffic is modeled through Passenger Car Equivalents (only PCEs in the following) for each type of vehicle (Roess and Prassas, 2014). The PCE of a specific type of vehicle may be assimilated to the number of the passenger cars which a heavy vehicle displaces from the traffic stream 
under prevailing traffic conditions (Kang and Nakamura, 2016; Mohan and Chandra, 2016); PCEs are deemed multiples of the effect of a passenger vehicle which is considered as base unit for comparison (Praveen and Arasan, 2013).

Several methods have been applied to determine PCEs for road entities. Literature refers that the traffic streams have been considered equivalent as they are moving at the same speed or density (Roess and Prassas, 2014; Giuffrè et al., 2017). Differently from macroscopic approaches, microscopic approaches consider the behavior of a vehicle only or two subsequent vehicles; thus, the question that has been done previously and also more recently in studies on the topic is "how many passenger vehicles are displaced from the traffic stream by one heavy vehicle under prevailing conditions?" (Roess and Prassas, 2014). A further issue concerns the definition of equivalence; there are different definitions of equivalency that address the assessment of the impact of heavy vehicles on the traffic parameters of interest.

Differences in the values of PCEs from different methods have been also found (e.g., Adnan, 2014; Zahiri and Chen, 2018). Raj et al. (2019) reviewed some methods used for estimating the equivalent factors for midblock sections and intersections under conditions of mixed traffic; they focused on the parameters influencing the PCE values and concluded that PCEs are not same both for nature of traffic (homogeneous and mixed traffic) and for type of road entity. The authors also highlighted that the effect of each vehicle type may vary due to traffic states; thus, they suggested the application of dynamic PCEs as traffic conditions change. However, they did not reach final conclusions, but highlighted directions for future research in estimating PCEs.

With specific reference to roundabouts, the influence of heavy vehicles on traffic performance is higher than on other atgrade intersections (e.g., Guerrieri et al., 2019). The curvilinear nature of the geometric design of the roundabouts impacts on the heavy vehicle paths (Pratelli, 2006; Fortuijn, 2009; Tollazzi, 2015). Despite heavy vehicles rarely exceed $30 \%$ of all vehicles especially in urban traffic, their longer lengths together with poorer performance have a quite different impact on traffic operations from the impact of the passenger cars (National Cooperative Highway Research Program, 2010). This impact is even greater at turbo roundabouts where drivers have to choose their direction before entering as a result of the spiraling shape and physical barriers marking the lanes on the circulatory roadway (Fortuijn, 2009; Tollazzi, 2015).

Roundabout design also characterizes the entry of vehicles that may face one or two circulating streams (Fortuijn, 2009; Giuffrè et al., 2012): vehicles entering the single-lane roundabout from single-lane entries approach vehicles driving counterclockwise the ring; in turn, based on desired destinations, vehicles entering the double-lane and turbo roundabouts may be accommodated on one of the two entry lanes (or both) and approach vehicles traveling in a lane of the two-lane ring (or both). This aspect should be also taken into account when entry capacity has to be estimated and the degrees of traffic functionality have to be assessed under heterogeneous traffic conditions.

It is well known that roundabout geometric design relies on the concept of design vehicle, namely the biggest vehicle that could be expected on road (e.g., Chevuri, 2018). However, there are often site-specific issues for heavy vehicle accommodation at roundabouts that can influence gap-acceptance behavior within mixed traffic streams and then the capacity analysis (Guerrieri et al., 2019). The method proposed by the Highway Capacity Manual $(2010 ; 2016)$ to assess the roundabout performance uses adjustments for each traffic flow rate in order to consider the traffic composition through PCEs; nevertheless, the equivalent factors for roundabouts fail to take account of type and performance of heavy vehicles, and traffic level.

Macioszek (2012) has identified the geometric parameters having influence on car equivalents of heavy vehicles at roundabouts. These factors include both properties of geometric design as outer diameter, width of the circulatory roadway and so on, and traffic properties as the amount of circulating and entering flows, as well as roundabout location, environment, and driver behavior, whose greater effects may be expected when unlimited traffic conditions and high degrees of saturated traffic occur. It follows that traffic analysis and the design process must take account of the vehicular composition and the influence of heavy vehicles operating in mixed traffic due to their influence on choices relating location, alignment of the approaches, shape and size of different types of roundabouts.

In light of the above considerations the hypothesis statement of the research is: "if we do not fix where studies and researches on calculation of PCEs for heavy vehicles at roundabouts are, we cannot recognize and assess the further research needs on this specific topic."

Different methodological approaches, as literature refers, have been used to determine PCEs. However, we still don't know which method is preferable. Thus, this paper attempts to review statistical methods and microscopic traffic simulation-based studies on calculation of PCEs at roundabouts. Studies related to the estimation of PCEs of heavy vehicles have been reviewed in order to gather and analyze information on this specific scientific question, to summarize their main conclusions and to obtain a certain level of evidence on the effects of heavy vehicles on capacity estimates at roundabouts.

In order to evaluate the state of knowledge and practice on the topic, the literature search has been done using the main available bibliographic database. First, studies on PCEs related to different road entities have been searched for; the field of interest has been then delineated with specific reference to roundabouts. These preliminary activities represented a step to find information on the possible criteria of equivalence used to show the effect of heavy vehicles on traffic variables for roads and intersections compared to a single passenger car. The results obtained in this study aim at providing an overview of the current knowledge concerning the estimation of PCEs at roundabouts, and can represent a guideline for planners, traffic engineers and managers to identify efficient ways to solve issues in the design and analysis of roundabouts under heterogeneous traffic conditions.

The organization of paper is as follows. Section A Literature Review on Passenger Car Equivalents at Roundabouts presents a literature review on Passenger Car Equivalents at roundabouts; it starts from a description of criteria of equivalence used for PCEs estimations for different types of road entities, and then focuses on statistical methods and microscopic traffic simulation studies 
for PCE estimations at roundabouts. Section Effects of Heavy Vehicles on Capacity and PCE Estimations at Roundabouts describes the effects on capacity and estimates of PCEs with specific reference to single-lane roundabouts. The last section concludes the paper.

\section{A LITERATURE REVIEW ON PASSENGER CAR EQUIVALENTS AT ROUNDABOUTS}

In this section, two main lines of research can be highlighted. The first line of research is related to how to explain equivalence used to calculate PCEs since many definitions are in use to analyze the influence of heavy vehicles in mixed traffic. Without being exhaustive but just to give some references, an overview of definitions of equivalence used to calculate PCEs for different road entities will be summarized in the next section.

The other line of research concerns the methods for estimating PCEs at roundabouts. It should be noted that each method of calculation may have influence on the determination of PCEs (e.g., Arasan and Arkatkar, 2010); with specific regard to roundabouts, few studies have been made both on the behavioral and physical processes at roundabout entries in presence of mixed fleets, and on PCE calculation for different layouts of roundabouts as worldwide in operation. Despite these limitations, the relevant information on statistical methods and traffic simulation-based methods for PCEs calculation at roundabouts as derived from the study collection process will be set out below.

\section{Criteria of Equivalence for the Estimation of PCEs: Some Examples}

In this section we will refer to criteria of equivalence for PCE estimations that have been stated both for road segments and for intersections.

In order to evaluate the effect of heavy vehicles on traffic parameters, different criteria of equivalence have been developed. Huber (1982) proposed a model to estimate PCE values for vehicles under free-flowing traffic and multi-lane conditions. The PCE values were determined by dividing the volumes of two streams (one mixed stream with trucks and passenger cars, and another stream only with passenger cars) at a common level of impedance. Beyond the numerical values obtained by Huber (1982), PCE values were also determined to relate to length and speed of the subject vehicles and to show their variation with the proportion of trucks in traffic. An application of the method of Huber (1982) was made by Giuffrè et al. (2015) to determine PCEs for freeway segments. PCEs were also derived for each different type of truck in traffic by De Marchi and Setti (2003); in this regard, a method to estimate an aggregate value of PCE was also proposed. The main findings of the study are referred to the measurement of the errors that may be attributed to the PCE values in mixed traffic; the study highlighted that the errors increased with the increase in density, but in a negligible way when densities $<10 \mathrm{veh} / \mathrm{km}$-lane occurred. The errors associated with equivalent flow rates calculated with aggregate values of PCEs were found smaller than errors associated with
PCEs calculated individually for each type of truck. However, further study was considered necessary for the validation of the proposed method.

Based on simulated flow-density curves PCEs were also estimated for different performance characteristics of vehicles, design features and traffic conditions on freeways and highways (Webster and Elefteriadou, 1999; Drakopoulos and Dehman, 2015; Shuguang and Ke, 2015), urban arterials (Chen et al., 2012; Sasikumar and Rajamma, 2018) and intersections (Mohan and Chandra, 2016). However, the results are beyond the scope of this paper and they are not directly applicable to flow conditions at intersections and roundabouts.

Literature refers a number of studies to estimate PCEs based on further criteria of equivalence. Anwaar et al. (2011) proposed a method that used the lagging headways consumed by subsequent vehicles in a traffic stream. This method makes it possible to determine site-specific PCEs and separate PCE values for each type of truck, but for uninterrupted flow conditions. The authors also predicted class-average lagging headways for some combinations of vehicles and then calculated PCE values by dividing the lagging headway of trucks and passenger cars. Although the authors were able to give reliable PCE values and then an appropriate description of the equivalent traffic stream, their results cannot be considered scalable to other contexts even though analogous in term of traffic. A further study by Al-Kaisy et al. (2002) based PCE calculations for heavy vehicles on queue discharge flow capacity and investigated the effect of heavy vehicles during congested traffic conditions at a merge area of an entry ramp and a reconstruction zone along a freeway. Observations of queue discharge flow capacity showed minimal variation especially when traffic streams were uniform and only made of passenger cars. The authors obtained a mean value of PCE equal to 2.36 for the first site, whereas Highway Capacity Manual (2000) presented 1.50; PCE values were 3.21 and 2.70 for the two travel directions at the second location, whereas Highway Capacity Manual (2000) presented values of 2.0. The results also showed that the PCE factor was independent from weather conditions and roadside maintenance works. A simulation-based procedure to estimate PCEs on urban arterials as a function of vehicle types and traffic volumes was also proposed and tested by Keller and Saklas (1984). They examined seven types of visual vehicles under different scenarios in terms of levels of service and signal setting types. PCE estimations resulted lower than those proposed by the Highway Capacity Manual (2000); however, their values increased as the traffic volumes forced traffic conditions, vehicles got bigger, and signal system approached the optimum.

Nassiri et al. (2017) based the PCE calculations on delay at signalized intersections; they collected data of traffic volumes, travel time by movement, geometry and signalization, and analyzed them in simulation environment. The main results were that PCE values varied from 1.10 to $1.65,1.07$ to 1.99 , and 0.76 to 3.60 for approaches with only one movement, with two or three movements, respectively. For the examined intersections the PCE value was close to the value of 2.0 proposed by Highway Capacity Manual (2010). However, no general conclusions can be drawn 
TABLE 1 | Summary of PCEs determined through analytical techniques.

\begin{tabular}{|c|c|c|c|}
\hline Country & Geometric design & On-field data or capacity analysis & PCE value \\
\hline $\begin{array}{l}\text { Australia (Troutbeck, 1988; Aumann and } \\
\text { Whitehead, 2015) }\end{array}$ & $\begin{array}{l}\text { Central island radius of double-lane } \\
\text { roundabouts from } 8.0 \text { to } 80.0 \mathrm{~m}\end{array}$ & $\begin{array}{l}\text { Capacity analysis by analytical } \\
\text { technique and gap-acceptance }\end{array}$ & $\begin{array}{l}2.0 \text { (trucks) } \\
3.0 \text { (articulated trucks) }\end{array}$ \\
\hline \multirow[t]{2}{*}{ Canada (Lee, 2015) } & $\begin{array}{l}\text { One 4-legged single-lane roundabout and two } \\
\text { 4-legged double-lane roundabout; outer } \\
\text { diameter }>50.0 \mathrm{~m}\end{array}$ & Capacity analysis based on field data & 1.5 or 2.5 (heavy trucks) \\
\hline & & & 1.0 or 1.5 (light trucks) \\
\hline France (CERTU, 1999; Guichet, 2005) & $\begin{array}{l}\text { Small to large single-lane and multi-lane } \\
\text { roundabouts (width: entry 3-11 m; splitter } \\
\text { island 0-70 m; exit 3.5-10.5 m; circle } \\
4.5-17.5 \mathrm{~m} \text { ) }\end{array}$ & $\begin{array}{l}\text { Capacity analysis by statistical } \\
\text { regression techniques (Mauro, 2010) }\end{array}$ & 2.0 \\
\hline Germany (Wu, 2001; Brilon, 2005) & $\begin{array}{l}\text { See German HCM (FGSV, 2015) Roundabout } \\
\text { geometry }\end{array}$ & $\begin{array}{l}\text { Capacity analysis by analytical } \\
\text { technique and gap-acceptance }\end{array}$ & 2.0 \\
\hline Poland (Macioszek, 2012) & Small single-lane roundabout & $\begin{array}{l}\text { Regression analysis and between } \\
\text { geometrical parameters vs. velocity of } \\
\text { vehicles }\end{array}$ & $\begin{array}{l}1.92 \text { to } 2.25 \text { as a function of } \\
\text { the velocity of vehicles } \\
\text { driving roundabouts }\end{array}$ \\
\hline Indiana, US (Overton, 2016) & $\begin{array}{l}\text { One four-legged roundabout with outer } \\
\text { diameter of } 48 \mathrm{~m}\end{array}$ & Capacity analysis based on field data & 3.37 (semi-trucks) \\
\hline $\begin{array}{l}\text { US (National Academies of Sciences, } \\
\text { 2007; National Cooperative Highway } \\
\text { Research Program, 2010) }\end{array}$ & $\begin{array}{l}\text { Four } 2 \text {-lane roundabouts with Outer diameter } \\
\text { from } 27.4 \text { to } 75.6 \mathrm{~m} \text {; rural and urban } \\
\text { double-lane roundabouts with outer diameter } \\
\text { of } 40.0 \text { to } 60.0 \mathrm{~m} \text { (Robinson et al., 2000) }\end{array}$ & $\begin{array}{l}\text { On field-based gap-acceptance } \\
\text { analysis and calibration of capacity } \\
\text { regression model }\end{array}$ & $\begin{array}{l}1.5 \text { (single-unit trucks) } \\
\text { (Robinson et al., 2000) or } \\
2.0 \text { otherwise (National } \\
\text { Academies of Sciences, } \\
\text { 2007) }\end{array}$ \\
\hline Switzerland (Bovy, 1991) & $\begin{array}{l}\text { Double-lane roundabouts with outer diameter } \\
\text { from } 22.0 \text { to } 35.0 \mathrm{~m} \text {; large roundabouts with } \\
\text { outer diameter from } 32.0 \text { to } 40.0 \mathrm{~m}\end{array}$ & $\begin{array}{l}\text { Capacity analysis by statistical } \\
\text { regression techniques }\end{array}$ & 2.0 \\
\hline
\end{tabular}

since too many (vehicular, geometric, and control) conditions should be considered at the same time.

With reference to roundabouts Giuffrè et al. (2017, 2018) proposed a criterion to determine PCEs that was relied on the equivalence of the capacity consumed by passenger vehicles and capacity consumed by heavy vehicles. For this purpose, the entry capacity corresponding to a demand of passenger vehicles $\left(C_{c a r}\right)$ and the entry capacity corresponding to a demand having a percentage $(p)$ of trucks $\left(C_{p}\right)$ were compared. AIMSUN (AIMSUN Dynamic Simulator User Manual, 2011) was used to build several scenarios where entering flows were characterized by different proportions of trucks. For double-lane and turbo roundabouts PCEs were specified by entry lane (Marino, 2014; Giuffrè et al., 2016, 2018). The PCEs resulted increasing as the circulating vehicles increased, especially with high amounts of trucks. Although the results were consistent with the conclusions drawn from Lee (2015), and could be considered closely related to choices such as driver behavior and the only class of heavy vehicles that was examined, the studies showed how to apply the criterion of equivalence for calculating PCEs at singlelane, double-lane and turbo roundabouts. The proposed method also results applicable to other layouts of intersections and roundabouts when the impact of heavy vehicles on traffic should be evaluated.

\section{Statistical Methods for PCEs Calculation}

Statistical methods for PCEs calculation are based on the process of gathering data and measuring information on variables of interest for the studied phenomenon. The collection of field data from numerous road entities often implies huge organizational efforts; but surveys are often insufficient, and differently from experiments in simulation environment do not allow to have homogenized traffic flows in the case of varying both geometric characteristics and traffic conditions at sites under examination (Valdez et al., 2011; List et al., 2015).

With reference to roundabouts, PCEs for heavy vehicles have not been always treated with the consideration which is certainly necessary both in planning and design studies, and in operational analyses. Evidence highlights that heavy vehicles impact on performances can vary in response to a change in the traffic demand. Geometric characteristics and traffic conditions, site and context of installation, users and driver behavior can affect equivalent factors, but further study should be done to consider the presence of heavy vehicles in mixed traffic, especially when high volumes move from one direction on the circulatory roadway and traffic streams can be highly saturated.

Some research efforts have been carried out to assess the heavy vehicle impact on performances, to determine PCEs used to transform mixed traffic streams into passenger car streams, and then to recalibrate the formulas of capacity to more appropriately account for heavy vehicles. In this view, Dahl and Lee (2012) assessed the influence of heavy vehicles on entry capacity observing the vehicular movements at eleven Canadian roundabouts. They found out higher values of critical headways and follow up headways for heavy vehicles than passenger vehicles and high effects of the central island diameter and the entry angle on the follow up headways in the truckinvolved vehicle-following cases. Capacity estimates were done 
considering a weighted average of the behavioral parameters of heavy vehicles and passenger vehicles by using traffic volumes as weights; a comparison of the estimated capacities with the on-field capacity values observed at three existing roundabouts was also done. Consistently with evidence-based literature the main results showed lower capacity reduction as the percentage of heavy vehicles increased; moreover, the models that used the adjusted behavioral parameters gave values of entry capacity better than the models that did not used them. However, the key strength of their research was pointing to the importance of the truck effect on capacity when high percentages of heavy vehicles are present in traffic.

Based on vehicle movement data collected from video cameras at three large roundabouts accommodating large trucks, also

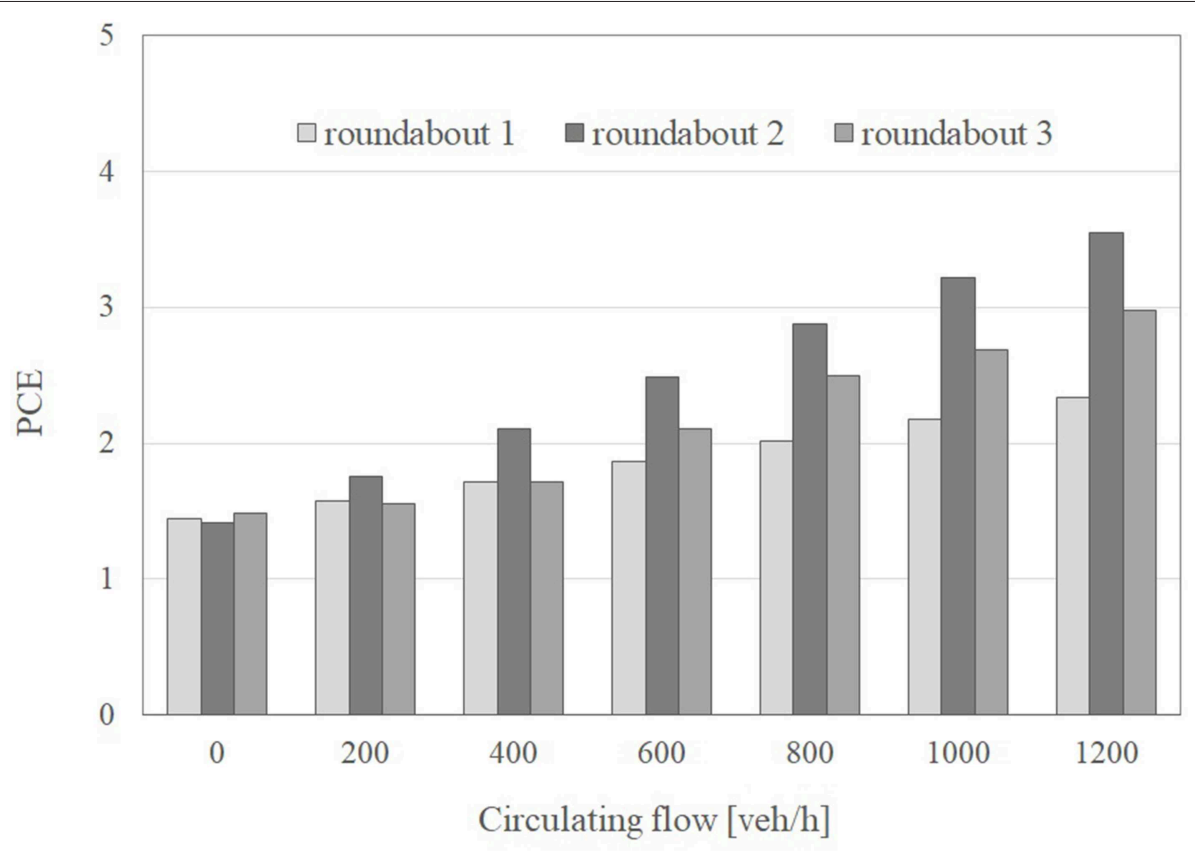

FIGURE 1 | PCE estimations for entry lanes with a similar capacity mechanism (Giuffrè et al., 2016, 2017, 2018). Note that roundabout 1 stands for single-lane roundabout, roundabout 2 stands for double-lane roundabout and roundabout 3 stands for turbo roundabout.

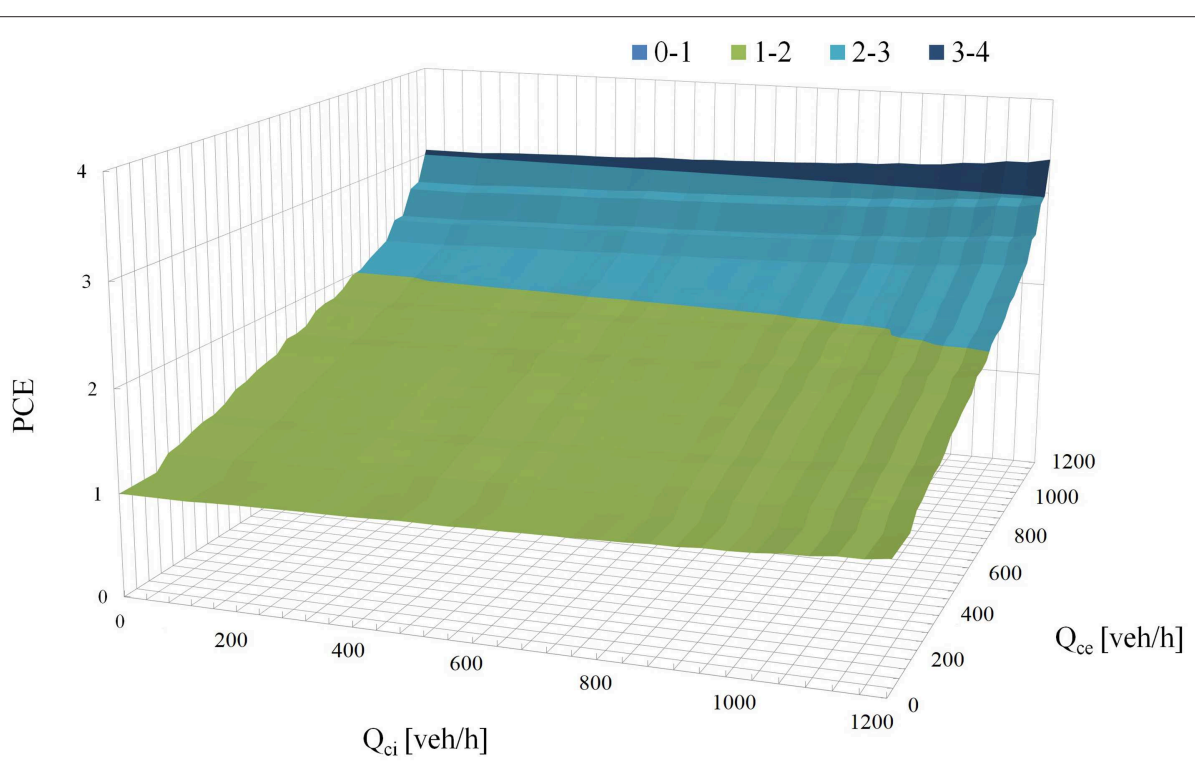

FIGURE 2 | PCE estimations for left entry lane at double-lane roundabout with a mean percentage of heavy vehicles between 10\% and 20\% (Marino, 2014; Giuffrè et al., 2016, 2018). Note that $Q_{c e}$ and $Q_{C i}$ are the circulating flows in the outer lane and in the inner lane of the ring, respectively. 


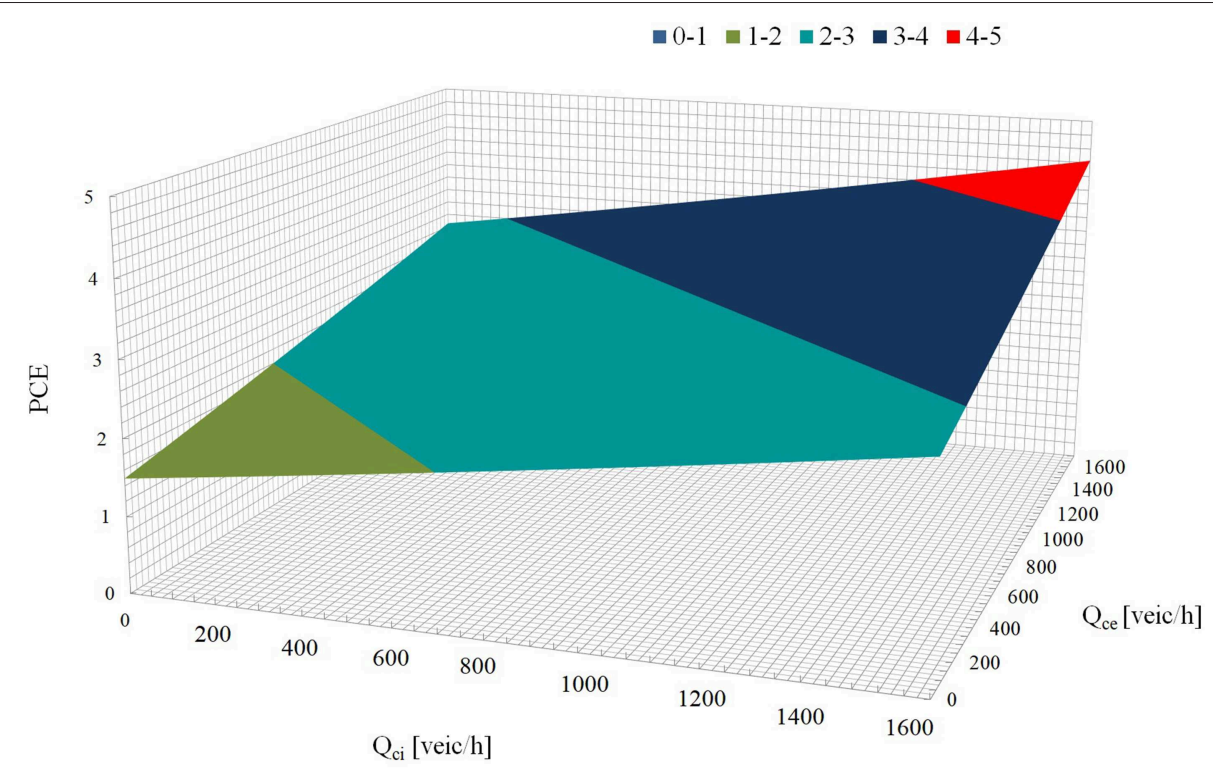

FIGURE 3 | PCE estimations for left lane on turbo roundabout minor entries with a $10 \%$ of heavy vehicles (Marino, 2014; Giuffrè et al., 2016). Note that $Q_{\mathrm{Ce}}$ and $\mathrm{Q}_{\mathrm{Ci}}$ are the circulating flows in the outer lane and in the inner lane of the ring, respectively.

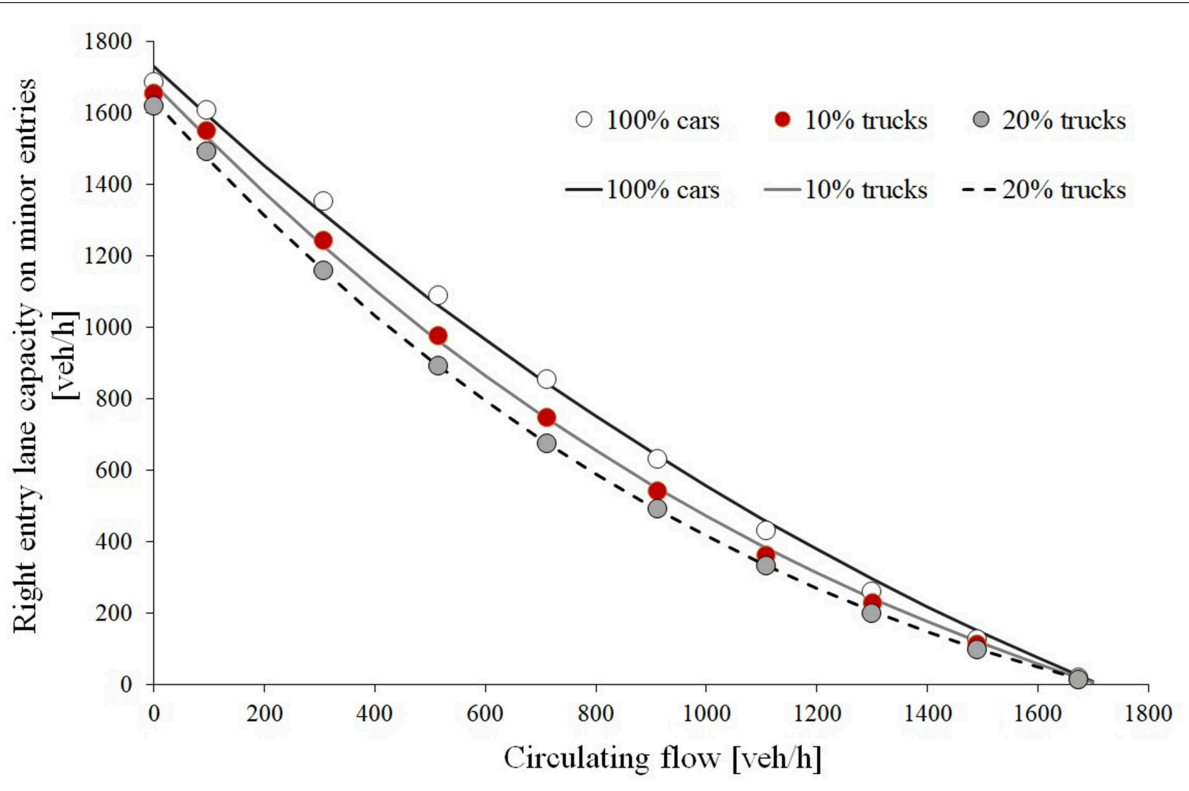

FIGURE 4 | Capacity functions and simulated data for the right-lane on minor entries at turbo roundabouts (Marino, 2014; Giuffrè et al., 2016).

Lee (2015) measured values of headways for differently sized vehicles and values of entry capacity at each site in 1 min fully saturated periods, and estimated PCEs. The author applied the equivalent factors to predict entry capacity using the model proposed by the Highway Capacity Manual (2010); adjustments to the behavioral headways were done on the basis of the different driver behavior of heavy vehicles and cars at entries. Differently from the default value of 2.0 for PCEs specified by the HCM, PCEs for heavy trucks and light trucks were found equal to 1.5 or 2.5 , and 1.0 or 1.5 , respectively. This highlighted that light trucks have to be weighted in a more appropriate way so as to take into account behavioral differences from heavy trucks during entry maneuvering. Lee (2015) also highlighted that adjustments to the behavioral headways of different heavy vehicles made with different weights (and not with a single weight) improved the accuracy of the capacity estimates. However, the author determined a constant value of PCE for each roundabout; thus, PCEs can be considered valid only for the roundabouts examined 
by Lee (2015), but not enough reliable to solve the problem of their generalization to other roundabouts. Moreover, Lee (2015) argued that driver's gap-acceptance could be affected by geometry, local driver's behavior and weather conditions at different sites; thus, the neglect of these effects on capacity estimates could have affected the results.

Robinson et al. (2000) determined a PCE value of 1.5 for single-unit trucks and a PCE value of 2.0 for trucks with trailer; the study proposed a procedure to predict capacity for double-lane roundabouts having an outer diameter ranging from 40.0 to $60.0 \mathrm{~m}$. Capacity prediction was based on a gapacceptance model incorporating limited priority behavior. A further analysis used count data of four multi-lane roundabouts having an outer diameter from 27.4 to $75.6 \mathrm{~m}$. The regression analysis required calibration to local conditions; behavioral headways were measured in the field. The PCE value of 2.0 was determined and used in the following edition of the Highway Capacity Manual (2010).

Overton (2016) determined the passenger car equivalent for heavy vehicles in a roundabout given that the value in the Highway Capacity Manual (2010) might be too low at 2.0; for this purpose, the heavy vehicle adjustment factor was calculated using the flows for the passenger vehicles and the total vehicular flow when trucks were present. Data supported this assumption and a weighted average car equivalent equal to 3.37 was determined for the roundabout. It should be noted that the weighted average was used to consider the effect of extremely high or low flows at the roundabout. Bearing in mind that data collection was limited to a one site, the author recommended repeating the study at different sites with moderate heavy truck traffic to understand the impact of heavy vehicles on entry capacity. However, the study is interesting for roundabout design (Overton, 2016): it shows that the heavy vehicle effect on traffic can be higher than two passenger vehicles and their impact on roundabout operations can vary with traffic demand.

Other studies were carried out by Macioszek (2010) that investigated the relationship between the traffic intensity and the value of PCEs; high PCEs were determined when high traffic intensities occurred at the examined circular intersections. The same author also analyzed the effect of geometric features as entry width, circulatory roadway width, outer diameter of the roundabout, and so on, on speeds (Macioszek, 2012). The main results were that PCE values varied from 1.92 to 2.25 varying the driver velocity on the ring roadway. Further research investigated the effect of bus on traffic driving roundabouts characterized by an outer diameter from 46.0 to $140.0 \mathrm{~m}$ (Tanyel et al., 2013). In order to prevent overdesigned roundabouts, different PCE values were used for major and minor entering flows.

Although there's been a lot of research on capacity modeling using statistical approaches and gap-acceptance (see e.g., Yap et al., 2013), further studies should be addressed to explain the complex processes that occur at roundabout entries when different percentages of heavy vehicles are mixed with passenger vehicles. Studies on the above line of research have attempted to translate the effect of geometric characteristics and traffic conditions at roundabouts, site and context of installation, users and driver behavior on equivalent factors, but their interest can be attributable to the methods applied to measure the heavy vehicles impact on road performances. For illustrative purposes, a summary of PCEs for heavy vehicles at roundabouts is shown in Table 1.

\section{Microsimulation-Based Studies for PCEs Calculation}

Microscopic traffic simulation models have been used for some time to estimate capacity and to determine the PCEs of heavy vehicles driving roundabouts. Experiments conducted applying microscopic simulation allow to produce different sets of traffic flows and to obtain homogenized flows for different geometric and traffic scenarios (List et al., 2015). However, the need to appropriately calibrate microscopic traffic simulation models requires further case studies with reference to different layouts of roundabouts.

A recent study by Kang and Nakamura (2016) has determined PCEs of heavy vehicles at single-lane roundabouts under Japanese traffic conditions. Speeds of passenger cars and heavy vehicles, and gap-acceptance parameters were the input parameters to simulation in VISSIM; calibration was done by using empirical data videotaped at a 4-legged roundabout with an outer diameter equal to $28.0 \mathrm{~m}$. Three traffic scenarios were simulated

TABLE 2 | Summary of PCEs proposed by the Highway Capacity Manual.

\begin{tabular}{|c|c|c|c|c|c|c|}
\hline \multirow[t]{3}{*}{ HCM model } & \multicolumn{6}{|c|}{ Geometric and gap-acceptance parameters } \\
\hline & \multirow{2}{*}{$\begin{array}{l}\text { Number of } \\
\text { entry lanes }\end{array}$} & \multirow{2}{*}{$\begin{array}{c}\text { Number of } \\
\text { circulating lanes }\end{array}$} & \multicolumn{2}{|c|}{ Critical headway $\mathbf{T}_{c}[\mathrm{~s}]$} & \multicolumn{2}{|c|}{ Follow up headway $T_{f}[s]$} \\
\hline & & & $\begin{array}{c}\text { Highway } \\
\text { Capacity Manual } \\
\text { (2010) }\end{array}$ & $\begin{array}{c}\text { Highway } \\
\text { Capacity Manual } \\
\text { (2016) }\end{array}$ & $\begin{array}{c}\text { Highway } \\
\text { Capacity Manual } \\
(2010)\end{array}$ & $\begin{array}{c}\text { Highway } \\
\text { Capacity Manual } \\
(2016)\end{array}$ \\
\hline$C=A \cdot e^{\left(-B \cdot Q_{C}\right)}$ & 1 & 1 & 5.193 & 4.990 & 3.186 & 2.609 \\
\hline$A=\frac{3600}{T_{f}}$ & 2 & 1 & 5.193 & 4.550 & 3.186 & 2.536 \\
\hline$B=\frac{T_{c}-\frac{T_{f}}{2}}{3600}$ & 1 & 2 & 4.133 & 4.320 & 3.186 & 2.536 \\
\hline (Right lane) & 2 & 2 & 4.113 & 4.320 & 3.186 & 2.536 \\
\hline (Left lane) & 2 & 2 & 4.293 & 4.650 & 3.186 & 2.667 \\
\hline
\end{tabular}


by assigning heavy vehicle traffic from the entry each time considered, from the other three entries but with the same percentage of heavy vehicles or from all the entries with equal percentage of heavy vehicles. The results highlighted that capacity values at entries decreased when the percentage of heavy vehicles grew and minor capacity occurred at high percentages of heavy vehicles. PCEs ranged from 1.5 to 1.9 to varying of the percentages of heavy vehicles in traffic, significantly raising as the circulating flow ranged from 0 to $600 \mathrm{pc} / \mathrm{h}$. Only when heavy vehicles were assigned from all the entries with equal percentage of heavy vehicles PCEs of the circulating flow resulted higher than PCEs of the entering flow (with a maximum value of 1.8) regardless of the percentage of heavy vehicles. However, the PCE values resulted smaller than the value of 2.0 given by Highway Capacity Manual (2010); thus, using a PCE of 2.0, entry capacity can be overestimated. However, the impacts of geometric features and traffic-related determinants could not be evaluated. Although the results of the study Kang and Nakamura (2016) are aligned with what could be observed in the field, they are only referable to the examined case of one type of roundabout. In this regard, more efforts should be made to examine the heavy vehicle impact on a wide number of sites together with the appropriate calibration of the gap-acceptance behavior of heavy vehicles in simulation environment. List et al. (2015) tried to refined the values of PCEs to transform mixed traffic into homogenized traffic at roundabouts; capacity functions were calibrated to consider trucks. The authors measured truck speeds to determine travel times through a roundabout. They noted needs of more research efforts to propose appropriate results for specific roundabout geometries (namely compact or conventional roundabouts), also using traffic simulation.

Giuffrè et al. (2017) determined PCEs for heavy vehicles at single-lane roundabouts. Calibration in AIMSUN (AIMSUN Dynamic Simulator User Manual, 2011) was done applying a genetic algorithm-based optimization procedure. An analogous procedure was used to calibrate AIMSUN (AIMSUN Dynamic Simulator User Manual, 2011) and to estimate PCEs of heavy vehicles at double-lane roundabouts (Giuffrè et al., 2018); in the last case PCEs were specified by each entry lane. Based on a criterion of equivalence that considers the capacity proportions of passenger vehicles and heavy vehicles (see section Criteria of Equivalence for the Estimation of PCEs: Some Examples), capacity functions having $100 \%$ passenger cars (the base curve) and for mixed fleets having $10 \%, 20 \%$, and $30 \%$ of trucks were estimated based upon regressions on simulated data. PCEs have been also estimated for basic turbo roundabouts by Giuffrè et al. (2016). The heavy vehicles simulated by Giuffrè et al. (2016) in AIMSUN (AIMSUN Dynamic Simulator User Manual, 2011) had characteristics of single unit trucks and trucks, namely a length from 6.00 to $10.00 \mathrm{~m}$, a width from 2.00 to $2.80 \mathrm{~m}$, the maximum acceleration from 0.6 to $1.80 \mathrm{~m} / \mathrm{s}^{2}$, the maximum deceleration from 4 to $6 \mathrm{~m} / \mathrm{s}^{2}$, the value of $85 \mathrm{~km} / \mathrm{h}$ for the maximum desired speed. Based on literature data as just referred, Figure 1 summarizes the estimation of PCEs for the entry lanes with a similar capacity mechanism (i.e., one antagonist traffic stream): the one-lane entry for single-lane roundabouts (roundabout 1), the right entry lane for double-lane roundabouts (roundabout
2), and turbo roundabouts (roundabout 3). This figure depicts a mean PCE value for more realistic percentages $(10 \%$ and $20 \%$ ) of heavy vehicles that occur frequently in real-world traffic. PCE increases when the circulating flow increases from $0 \mathrm{veh} / \mathrm{h}$ onwards: for roundabout 1 the equivalent factors keep values around 2, but it does not exceed 2 for the changes of the circulating flow here considered; thus, setting a value of 2.0 (see Highway Capacity Manual, 2010), the effect of heavy vehicles on traffic quality is overestimated. With reference to the single-lane layout (roundabout 1 ) the results in the figure above mentioned is consistent with what Kang and Nakamura (2016) observed at a single-lane site. For roundabouts 2 and 3, an analogous trend is shown when the circulating flow rises from 0 to 600 veh/h (see Figure 1), while PCE values exceed 2 only when the circulating flow is $>600 \mathrm{veh} / \mathrm{h}$, or the circulating flow tends to reach saturation. Figures 2, 3 give examples of the influence of heavy vehicles on the left lane operations at double-lane and turbo layouts, respectively. In both cases PCE depends on the circulating flows driving the ring lanes. More precisely, Figure 2 shows simulation-based PCE estimations for left entry lane on double-lane roundabouts with reference to a mean percentage of heavy between $10 \%$ and $20 \%$. In this regard, no significant difference in PCEs resulted when one or the other percentage of heavy vehicles has been used to simulate mixed fleets of passenger cars and heavy vehicles (Giuffrè et al., 2018).

Figure 3 shows PCE estimations at left lane on turbo roundabout minor entries when a mixed traffic with $10 \%$ of heavy vehicles was simulated in AIMSUN (AIMSUN Dynamic Simulator User Manual, 2011; Giuffrè et al., 2016). It should be noted that PCE values remain below 4 with 10 or $20 \%$ of heavy vehicles at double-lane roundabouts (see Figure 2), while a PCE just over 4 should be reached even with $10 \%$ of heavy vehicles in traffic at turbo roundabouts (see Figure 3) (Giuffrè et al., 2016). Again, when a PCE of 2.0 is used (see Highway Capacity Manual, 2010 for roundabouts), the influence of heavy vehicles on traffic quality could be underestimated. In all the cases as above referred, PCEs increase when circulating traffic increases.

This is evidence that size and performances of heavy vehicles limit their maneuvering needs especially at entries and thereby influence the gap-acceptance behavior. However, literature that has been mentioned above reports studies that included only a part of heavy vehicles used to estimate the values of equivalent factors for roundabouts proposed by the Highway Capacity Manual (2010); in any case the results showed in Figures 2, 3 are consistent with the results already highlighted by Lee (2015), namely that the equivalent factors depend on traffic conditions.

\section{EFFECTS OF HEAVY VEHICLES ON CAPACITY AND PCE ESTIMATIONS AT ROUNDABOUTS}

The now-familiar capacity models available for roundabouts at steady-state conditions are currently classified into formulas that contain information about: the number of circulating and entry lanes (Brilon et al., 1997; Wu, 2001; Brilon, 2005), or the size of further planimetric features of the roundabout and 


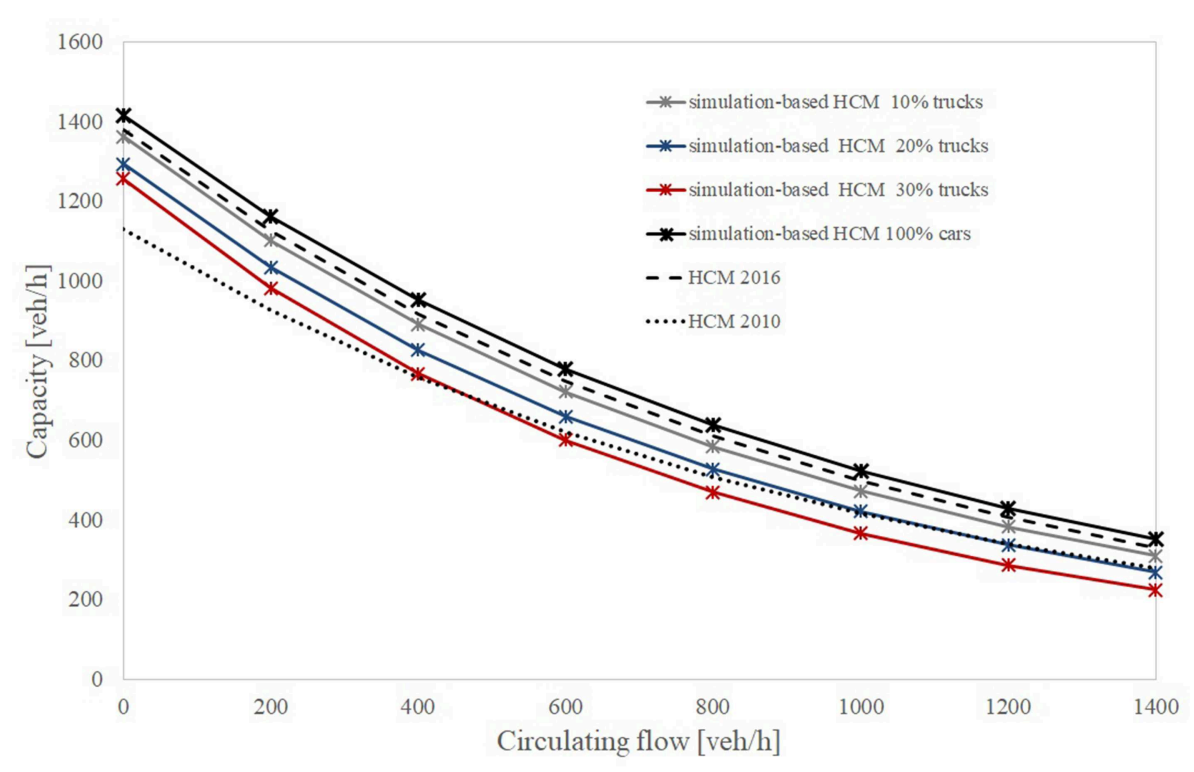

FIGURE 5 | Capacity functions by Highway Capacity Manual (2010; 2016) models and Giuffrè et al. (2017).

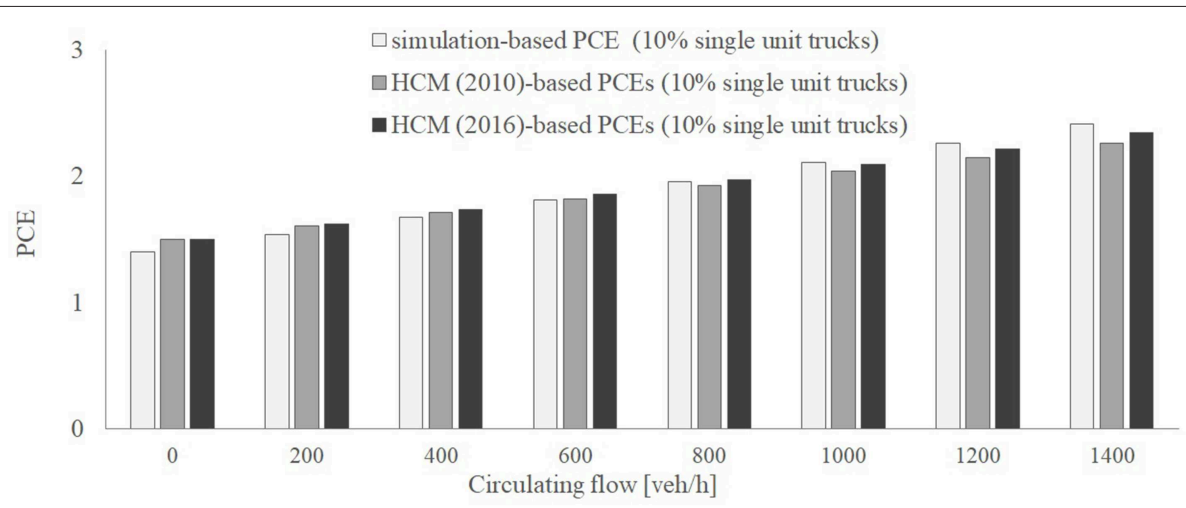

FIGURE 6 | PCEs calculated using the Highway Capacity Manual (2010; 2016) and simulation-based approach by Giuffrè et al. (2017) for a single unit truck percentage of $10 \%$.

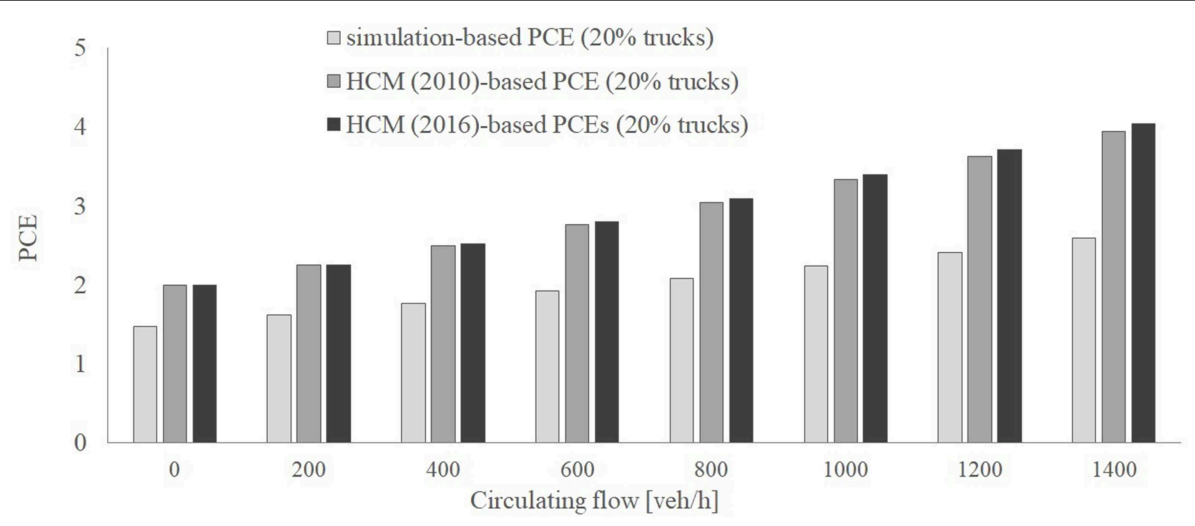

FIGURE 7 | PCEs calculated using the Highway Capacity Manual (2010; 2016) and simulation-based approach by Giuffrè et al. (2017) for a truck percentage of 20\%. 
the circulating flow as antagonist flow (Kimber, 1980), or even the users' behavior through critical and follow-up headways together with geometric aspects (Louah, 1992). Only the Swedish model for entry capacity estimation uses the percentage of heavy vehicles among the input parameters (CAPCAL2, 1995).

Kimber (1989) compared capacity estimations of several gapacceptance models, but they were found mutually inconsistent. It is well-known that there are several factors which may potentially influence the behavior of an average driver at roundabout approaches as the percentage of heavy vehicles, conflicting and exiting flows, geometric design elements and so on. Thus, with a view to enhancing the quality of the estimates and performance evaluation at roundabouts, calibration of a capacity model to local conditions is a necessary task though not easy to do (Mauro, 2010).

According to the studies referred in the previous section, heavy vehicles contribute to reduce entry capacity and this effect is more pronounced in presence of higher percentages of heavy vehicles in the entering traffic. By way of example, Figure 4 shows the capacity functions estimated by non-linear regression analysis of simulation data after calibration of a turbo roundabout in AIMSUN (AIMSUN Dynamic Simulator User Manual, 2011); different percentages of passenger cars and single unit trucks $(0,10 \%$, and $20 \%$ of trucks) in traffic were used. Note that capacity functions in Figure $\mathbf{4}$ are referred to the right-lane on minor entries where the capacity mechanism happens between entering vehicles and vehicles circulating on the outer lane of the turbo circle.

The Highway Capacity Manual $(2010 ; 2016)$ method presents an exponential function to estimate entry capacity at single-lane and multi-lane roundabouts; the entry lane capacity depends on the circulating flow. Table 2 shows for informative purposes the parameters that changed from the 5 th to 6 th edition of the HCM. One can observe a decrease of the critical and follow up headways in the Highway Capacity Manual (2016) compared to Highway Capacity Manual (2010) since users are becoming even more familiar in using roundabouts and need smaller gaps to enter the roundabouts. This also demonstrates the corresponding increase in entry capacity. A further method to estimate capacity at each entry of roundabouts has been proposed by Brilon (2005), where the entry lane capacity is a function of critical and follow up headways, minimum headway of the circulating vehicles, circulating flows, the number of circulating lanes and entry lanes. Under the German conditions the values of the critical gap, the follow up headway and the minimum headway between circulating vehicles were estimated equal to 4.1, 2.9, and $2.1 \mathrm{~s}$, respectively.

Figure 5, by way of example, shows the capacity trends at single-lane roundabouts built using the capacity formulas in Table 2. Note that the functions in Figure 5 named "simulationbased HCM" refer to the HCM model that has been recalibrated using the values of the behavioral headways estimated by Giuffrè et al. (2017) with percentages of heavy vehicles from 0 to $30 \%$. Thus, the higher the heavy vehicle percentages, the greater the amount of capacity reduction.

To test AIMSUN (AIMSUN Dynamic Simulator User Manual, 2011) reliability in producing appropriate capacity data, AIMSUN-based PCE values from Giuffrè et al. (2017) and PCE values based on the HCM models $(2010,2016)$, that were recalibrated using behavioral headways adjusted for heavy vehicles, were compared. In this regard, literature refers that the behavioral headways can be adjusted to take into account the influence of heavy vehicles on capacity by using the factor $f_{H V}$ (see Lee, 2015); thus, the headways in Table 2 for singlelane roundabouts were divided by the factor $f_{H V}$ calculated with reference to realistic percentages of heavy vehicles in traffic. PCEs were determined using the equivalence criterion as addressed in section Criteria of Equivalence for the Estimation of PCEs: Some Examples.

By way of examples, Figures 6, 7 show the results of the comparison made with reference to single-lane roundabouts for percentages of single unit trucks of $10 \%$ and $20 \%$, respectively. The comparisons show consistent trends for PCEs calculated using the Highway Capacity Manual (2010; 2016) and simulation-based approach by Giuffrè et al. (2017). The difference of PCEs in Figure 7 may be accounted to the effects of local traffic conditions, physical characteristics of the heavy vehicles that were used and the methods applied to determine PCEs that could have had an influence on the results. In any case, direction is that PCEs should vary with traffic conditions (see also Lee, 2015). Given the type of comparison, findings cannot be definitive, but they detect further developments of the research on the topic. According to Raj et al. (2019), however, more vehicle types, variability within a class of heavy vehicles, and lane use could make very complex the evaluation of heterogeneous traffic due to the parameters needed to appropriately estimate PCEs.

\section{CONCLUSIONS}

Decisions to be taken in the design process and traffic analysis should also rely on heavy vehicles and their impacts on operational performances as result of the influence that they might have on some choices relating to locations, approach alignment, size and shape of a particular type of roundabout. The relevance of Passenger Car Equivalents is attributable to road entities which operate under mixed traffic. However, few studies have been made both on the behavioral and physical processes at roundabout entries in presence of mixed fleets, and on PCE calculation for different layouts of roundabouts as worldwide in operation.

The literature review on the calculation of PCEs at roundabouts allows us to make some conclusions. Overall, despite physical and behavioral processes at roundabouts that operate under mixed traffic are not yet fully known, various studies agree that heavy vehicles contributed to reduce the entry capacity and this reduction is even more marked when achieved through increasing percentage of heavy vehicles entering the roundabout. The space and maneuvering needs of heavy vehicles are limited by the dimensional, kinematic, power and braking characteristics varying by type of vehicle; as a consequence, the heavy vehicle behavior at entry is influenced.

Equivalent coefficients that pertain to roundabouts have been calculated by statistical methods and microscopic traffic 
simulation models. Many differences were detected at times among the values of PCEs calculated applying different methods. Literature, in this regard, highlights that each different methodological approach may have affected each PCE determination. Despite the importance of the application of PCEs in determining the level-of-service for roads and intersections, we do not have a detailed account of which method is preferable. Microsimulation represents an appropriate tool to assess changes in traffic quality; indeed, a microscopic traffic simulation model allows to obtain traffic scenarios not directly observable on field and to produce their replication in order to have a sufficient amount of data to be interpreted.

Finally, based on the studies examined in this review, there is evidence that PCEs mainly change with:

- the percentage of heavy vehicles in traffic;

- the layout of roundabout (single-lane roundabout and multilane roundabout where PCEs can be diversified for each entry lane);

- the geometric characteristics (as outer diameter, size of central island, number of entries, circulating and exit lanes, and so on).

It should be noted that in all the studies as above referred, only a part of heavy vehicles used to estimate the HCM PCE values were time to time considered; however, the results agree that equivalent factors depend on traffic conditions and the amount of circulating flow, and can vary with the roundabout layout.

Many research themes are still open for roundabouts application and future studies should focus on calculation of PCEs for further types of heavy vehicles, also in presence of non-motorized vehicles; on optimization of calibration

\section{REFERENCES}

Adnan, M. (2014). Passenger car equivalent factors in heterogenous traffic environment-are we using the right numbers? Procedia Eng. 77, 106-113. doi: 10.1016/j.proeng.2014.07.004

AIMSUN Dynamic Simulator User Manual (2011). Transport Simulation System (TSS) Version 8. Barcelona: AIMSUN.

Al-Kaisy, A., Hall, F. L., and Reisman, E. S. (2002). Developing passenger car equivalents for heavy vehicles on freeways during queue discharge flow. Transport. Res. Part A 36, 725-742. doi: 10.1016/S0965-8564(01) 00032-5

Anwaar, A., Van Boxel, D., Volovski, M., Anastasopoulos, P. C., Labi, S., and Sinha, K. C. (2011). Using lagging headways to estimate passenger car equivalents on basic freeway sections. J. Transp. InstituteTransp. Eng. 2, 5-17.

Arasan, V. T., and Arkatkar, S. S. (2010). Microsimulation study of effect of volume and road width on PCU of vehicles under heterogeneous traffic. J. Transport. Eng. 136, 1110-1119. doi: 10.1061/(ASCE)TE.1943-5436.0000176

Asaithambi, G., Sekar Mourie, H., and Sivanandan, R. (2017). Passenger car unit estimation at signalized intersection for non-lane based mixed traffic using microscopic simulation model. Period. Polytech. Transport. Eng. 45, 12-20. doi: 10.3311/PPtr.8986

Aumann, P., and Whitehead, M. (2015). Guide to Road Design Part 4bRoundabouts, Austroads, Sydney.

Bovy, P. H. (1991). Zusammenfassung des Schweizerischen Kreiselhandbuchs [Summary of Swiss Roundabout Guide]. Straße und Verkehr 3.

Brilon, W. (2005). "Roundabouts: a state of art in Germany," in 4th International Conference on Roundabouts (Washington, DC: Transportation Research Board). parameters of microscopic traffic simulation models in view of PCEs calculations; on assessment of changes to traffic flow characteristics and level-of-service due to the introduction of new vehicle technologies. Findings from such studies could provide new evidence for the ways to address problems that transportation engineers could face using traffic microsimulation in the professional approach.

\section{DATA AVAILABILITY}

The datasets analyzed for this study are available from the corresponding author upon request.

\section{AUTHOR CONTRIBUTIONS}

TG and AG designed the organization of the paper and criteria of bibliographic research. FA made the bibliographic research and prepared figures. All of the authors read the paper. AG wrote the paper. OG provided oversight for the capacity analysis methodology and coordinated the activities. MT collaborated to the final editing of the paper.

\section{ACKNOWLEDGMENTS}

Special thanks go to Engineers Fabio Galatioto (Transport Systems Catapult, UK), Sergio Marino and Antonino Sferlazza (University of Palermo, Italy) for their contributions and efforts as co-authors in past research activities consistent with this specific topic as documented by the bibliographic references.

Brilon, W., Wu, N., and Bondzio, L. (1997). "Unsignalized intersections in Germany-a state of the art 1997," in Proceedings of the Third International Symposium on Intersections Without Traffic Signals (Portland, OR).

CAPCAL2 (1995). Model Description of Roundabouts. Publication 1995:009E. Borlänge: Swedish National Road Administration.

CERTU (1999). Carrefours Urbains Guide. Lyon: CERTU.

Chen, X., Han, H., and Lin, B. (2012). Developing bicycle equivalents for mopeds in Shanghai, China. Transport. Res. Record J. Transport. Res. Board 2317, 60-67. doi: $10.3141 / 2317-08$

Chevuri, P. K. (2018). Trucks at roundabouts: a synthesis study. J. Transport. Technol. 8, 65-74. doi: 10.4236/jtts.2018.81004

Dahl, J., and Lee, C. (2012). Empirical estimation of capacity for roundabouts using adjusted gap-acceptance parameters for trucks. Transport. Res. Record 2312, 34-45. doi: 10.3141/2312-04

De Marchi, S. H., and Setti, J. R. (2003). Limitations of passenger-car equivalent derivation for traffic streams with more than one truck type. Transport. Res. Record 1852, 96-104. doi: 10.3141/1852-13

Drakopoulos, A., and Dehman, A. (2015). Field-derived freeway passenger car equivalents for congested conditions. Transport. Res. Record J. Transport. Res. Board 2483, 111-119. doi: 10.3141/2483-13

FGSV (2015). Handbuch für die Bemessung von Stra ßenverkehrsanlagen (HBS) [German Highway Capacity Manual]. Cologne: Forschungsgesellschaft für Stra Ben und Verkehswesen.

Fortuijn, L. (2009). Turbo roundabouts: estimation of capacity. Transport. Res. Record 2130, 83-92. doi: 10.3141/2130-11

Giuffrè, O., Granà, A., Giuffrè, T., and Marino, R. (2012). Researching a capacity model for multilane roundabouts with negotiation of the right-of-way between antagonist traffic flows. Modern Appl. Sci. 6, 2-12. doi: 10.5539/mas.v6n5p2 
Giuffrè, O., Granà, A., Marino, S., and Galatioto, F. (2016). Microsimulationbased passenger car equivalents for heavy vehicles driving turbo-roundabouts. Transport 31, 295-303. doi: 10.3846/16484142.2016.1193053

Giuffrè, O., Granà, A., Mauro, R., Bastos Silva, A., and Chiappone, S. (2015). Developing passenger car equivalents for freeways by microsimulation. Transport. Res. Procedia 10, 93-102. doi: 10.1016/j.trpro.2015.09.059

Giuffrè, O., Granà, A., Tumminello, M. L., and Sferlazza, A. (2017). Estimation of passenger car equivalents for single-lane roundabouts using a microsimulation-based procedure. Expert System Appl. 79, 333-347. doi: 10.1016/j.eswa.2017.03.003

Giuffrè, O., Granà, A., Tumminello, M. L., and Sferlazza, A. (2018). Capacitybased calculation of passenger car equivalents using traffic simulation at double-lane roundabouts. Simulation Modelling Pract. Theory 81, 11-30. doi: 10.1016/j.simpat.2017.11.005

Guerrieri, M., Mauro, R., and Tollazzi, T. (2019). Turbo-roundabout: case study of driver behavior and kinematic parameters of light and heavy vehicles. J. Transport. Eng. Part A Systems 145:05019002. doi: 10.1061/JTEPBS.0000241

Guichet, B. (2005). "Evolution of roundabouts in France and new use," in National Roundabout Conference 2005 (Vail, CO: TRB Transportation Research).

Highway Capacity Manual (2000). Special Report n. 209. Washington, DC: Transportation Research Board.

Highway Capacity Manual (2010). Highway Capacity Manual, 5th Edn. Washington, DC: Transportation Research Board.

Highway Capacity Manual (2016). Highway Capacity Manual, 6th Edn. Washington, DC: Transportation Research Board.

Huber, M. J. (1982). Estimation of passenger-car equivalents of trucks in traffic stream. Transport. Res. Record 869, 60-70.

Kang, N., and Nakamura, H. (2016). An analysis of heavy vehicle impact on roundabout entry capacity in Japan. Transport. Res. Procedia 15, 308-318. doi: 10.1016/j.trpro.2016.06.026

Keller, E. L., and Saklas, J. G. (1984). Passenger car equivalents from network simulation. J. Transport. Eng. 110, 397-411. doi: 10.1061/(ASCE)0733-947X(1984)110:4(397)

Kimber, R. M. (1980). The Traffic Capacity of Roundabouts. TRRL Laboratory Report 942. Crowthorne: TRRL.

Kimber, R. M. (1989). Gap-acceptance and empiricism in capacity prediction. Transport. Sci. 23, 100-111. doi: 10.1287/trsc.23.2.100

Kiran, S., and Verma, A. (2016). Review of studies on mixed traffic flow: perspective of developing economies. Transp. Develop. Econ. 2, 1-16. doi: $10.1007 /$ s40890-016-0010-0

Lee, C. (2015). Developing passenger-car equivalents for heavy vehicles in entry flow at roundabouts. J. Transport. Eng. 141:1. doi: 10.1061/(ASCE)TE.1943-5436.0000775

List, G. F., Yang, B., and Schroeder, J. B. (2015). On the treatment of trucks in roundabout analyses. Transport. Res. Record 2483, 140-147. doi: 10.3141/2483-16

Louah, G. (1992). "Panorama critique des modeles français de capacité des carrefours giratoires," in Actes du Séminaire International "Giratoires 92," SETRA (Nantes).

Macioszek, E. (2010). Analiza wpływu stopnia obciazenia ruchem na wartósc współczynnika przeliczeniowego dla pojazdów ciezkich na skrzyzowaniach typu rondo [Analysis of the influence of the traffic load on the value of car equivalents for heavy vehicles on roundabouts]. Logistyka 6, 2071-2079.

Macioszek, E. (2012). "Geometrical determinants of car equivalents for heavy vehicles crossing circular intersections," in Telematics in the Transport Environment. Communications in Computer and Information Science, Vol. 329, ed J. Mikulski (Berlin Heidelberg: Springer), 221-228. doi: 10.1007/978-3-642-34050-5_25

Marino, S. (2014). Performance Levels of Traditional and Innovative Roundabouts in Comparison. The Impact of Heavy Vehicles. $\mathrm{PhD}$ thesis. University of Palermo.

Mauro, R. (2010). Calculation of Roundabouts: Capacity, Waiting Phenomena and Reliability. Berlin Heidelberg: Springer-Verlag.

Mohan, M., and Chandra, S. (2016). Concept of queue clearance rate for estimation of equivalency factors at priority junctions. Can. J. Civil Eng. 43, 593-598. doi: 10.1139/cjce-2015-0396

Nassiri, H., Tabatabaie, S., and Sahebi, S. (2017). Delay-based passenger car equivalent at signalized intersections in Iran. Promet Traffic Transp. 29, 135-142. doi: 10.7307/ptt.v29i2.2040
National Academies of Sciences, Engineering, and Medicine (2007). Roundabouts in the United States. Washington, DC: The National Academies Press.

National Cooperative Highway Research Program (2010). Roundabouts: An Informational Guide.

Overton, R. (2016). Evaluation of Heavy Vehicles on Capacity Analysis for Roundabout Design. NEXTRANS Report No. 180TUY2.2. USDOT Region University Transportation Center. Available online at: https://www.purdue. edu/discoverypark/nextrans/assets/pdfs/new/180TUY2.2\%20Evaluation $\% 20$ of $\% 20$ Heavy\%20Vehicles\%20on\%20Capacity\%20Analysis\%20for \%20Roundabout\%20Design_final\%20report.pdf (accessed April 24, 2019).

Pratelli, A. (2006). Design of modern roundabouts in urban traffic systems. WIT Transac. Built Environ. 89, 83-93. doi: 10.2495/UT060091

Praveen, P. S., and Arasan, V. T. (2013). Influence of traffic mix on PCU value of vehicles under heterogeneous traffic conditions. Int. J. Traffic Transport. Eng. 3, 302-330. doi: 10.7708/ijtte.2013.3(3).07

Raj, P., Sivagnanasundaram, K., Asaithambi, G., and Ravi Shankar, A. U. (2019). Review of methods for estimation of passenger car unit values of vehicles. J. Transport. Eng. Part A Systems 145:234. doi: 10.1061/JTEPBS.00 00234

Robinson, B. W., Rodegerdts, L., Scarborough, W., Kittelson, W., Troutbeck, R., Brilon, W., et al. (2000). Roundabouts: An Informational Guide, 1st Edn. Report No. FHWA-RD-00-067 FHWA. Washington, DC: Federal Highway Administration-United States Department of Transportation.

Roess, R. P., and Prassas, E. S. (2014). The Highway Capacity Manual: A Conceptual and Research History. Springer Tracts on Transportation and Traffic 5, Vol. 1. London: Springer. doi: 10.1007/978-3-319-05786-6

Sasikumar, S., and Rajamma, A. (2018). Development of passenger car unit based on acceleration noise for urban arterials. Proc. Inst. Civil Eng. Transport. 171, 331-338. doi: 10.1680/jtran.17.00073

Shuguang, L., and Ke, W. (2015). "The estimation of passenger car equivalent for highway under oversaturated conditions," in International Conference on Transportation Information and Safety (Wuhan: INSPEC).

Tanyel, S., Caliskanelli, S. P., Aydn, M. M., and Utku, S. B. (2013). An investigation of heavy vehicles effect on traffic circles. Digest 2013, 1675-1700.

Tollazzi, T. (2015). Alternative Types of Roundabouts: An Informational Guide. New York, NY: Springer Tracts on Transportation and Traffic.

Troutbeck, R. J. (1988). "Current and future Australian practice for the design of unsignalised intersections," in Intersections without Traffic Signals, ed W. Brilon (Berlin: Springer-Verlag), 1-19. doi: 10.1007/978-3-642-833 73-1_1

Valdez, M., Cheu, R. L., and Duran, C. (2011). Operations of modern roundabout with unbalanced approach volumes. Transport. Res. Record 2265, 234-243. doi: $10.3141 / 2265-26$

Webster, N., and Elefteriadou, L. (1999). A simulation study of truck passenger car equivalents (PCE) on basic freeway sections. Transport. Res. Part B 33, 323-336. doi: 10.1016/S0965-8564(98)00036-6

$\mathrm{Wu}, \mathrm{N}$. (2001). A universal procedure for capacity determination at unsignalized (priority-controlled) intersections. Transport. Res. Part B 35, 593-623. doi: 10.1016/S0191-2615(00)00012-6

Yap, Y. H., Gibson, H. M., and Waterson, B. J. (2013). An international review of roundabout capacity modeling. Transport. Rev. 33, 593-616. doi: 10.1080/01441647.2013.830160

Zahiri, M., and Chen, X. (2018). Measuring the passenger car equivalent of small cars and SUVs on rainy and sunny days. Transport. Res. Record J. Transport. Res. Board 2672, 110-119. doi: 10.1177/03611981187 58638

Conflict of Interest Statement: The authors declare that the research was conducted in the absence of any commercial or financial relationships that could be construed as a potential conflict of interest.

Copyright (C) 2019 Giuffrè, Granà, Giuffrè, Tumminello and Acuto. This is an openaccess article distributed under the terms of the Creative Commons Attribution License (CC BY). The use, distribution or reproduction in other forums is permitted, provided the original author(s) and the copyright owner(s) are credited and that the original publication in this journal is cited, in accordance with accepted academic practice. No use, distribution or reproduction is permitted which does not comply with these terms. 